\title{
A Case of an Urachal Remnant Abscess without Omphalitis
}

\author{
Keiichiro Kita
}

Key words: urachal remnant, abscess, omphalitis, Carnett's sign

(Intern Med 60: 1137-1138, 2021)

(DOI: 10.2169/internalmedicine.5999-20)

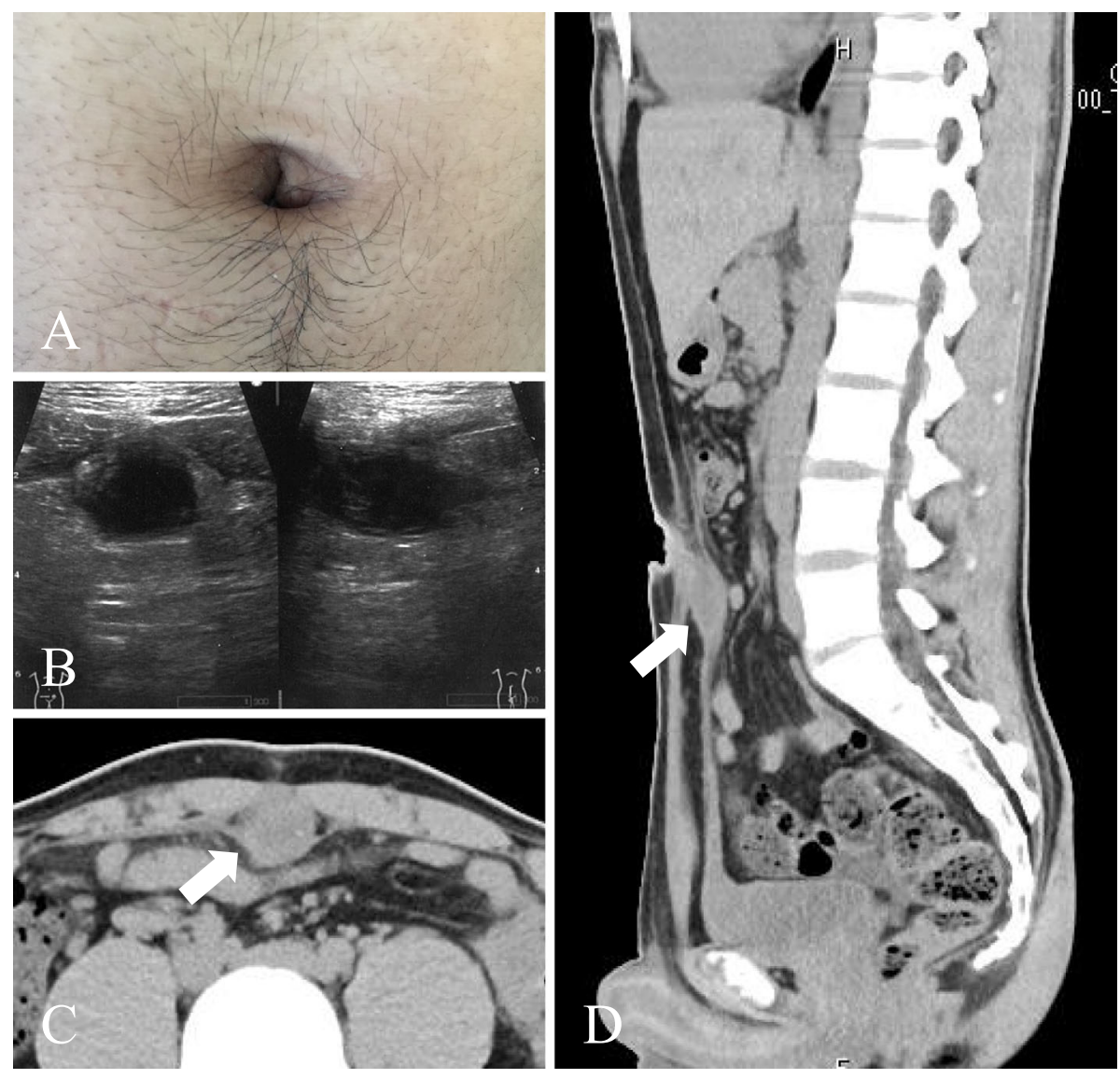

Picture.

A 20-year-old Japanese man presented with a three-day history of progressive lower abdominal pain and low-grade fever. He had no nausea, diarrhea, or urinary symptoms. Physical examination found the abdomen to be soft and flat. The umbilicus appeared to be normal without any discharge or swelling (Picture A). Percussion tenderness and the heel drop test (a test for intraperitoneal tenderness) were positive below the umbilicus area. Carnett's sign (a test for parietal tenderness) was also positive. Abdominal ultrasonography revealed a hypoechoic lesion under the rectus muscle (Picture B), and a computed tomography scan confirmed this diagnosis (Picture C, D).

Although pus discharge from the umbilicus is an important clinical clue that can lead to a diagnosis of an urachal abscess (1), a few patients show no signs of omphalitis (2). In this case, the physical findings suggested an abnormality in the midline space between the peritoneum and the abdominal wall. 
The author states that he has no Conflict of Interest (COI).

\section{References}

1. Schiffman JS. Urachal remnants in patients presenting to the emergency department with abdominal pain. Int J Emerg Med 55: 333-338, 2018.
2. Tazi F, Ahsaini M, Khalouk A, et al. Abscess of urachal remnants presenting with acute abdomen: a case series. J Med Case Rep 6: 226, 2012.

The Internal Medicine is an Open Access journal distributed under the Creative Commons Attribution-NonCommercial-NoDerivatives 4.0 International License. To view the details of this license, please visit (https://creativecommons.org/licenses/ by-nc-nd/4.0/).

(C) 2021 The Japanese Society of Internal Medicine Intern Med 60: 1137-1138, 2021 